\title{
Demobilized Officers Incentive System and Model Design
}

\author{
Jianjun Han, Xiaolan Lu \\ Logistics University of People's Armed Police Force \\ Tianjin, P.R. China \\ 1600644691@qq.com
}

\begin{abstract}
How to motivate the officers to be at ease is the important problem of the relationship between the core fighting force of the army. At present, the military general use of the task of the lack of a lack of strategic thinking on the overall organizational strategy, long-term incentive system is too simple, can not meet the requirements of strategic incentive mechanism. In order to realize the strategic incentive target, relying solely on the promotion incentive is not enough, must contact the switch system. Therefore, this paper proposes the resettlement system into the incentive system, demobilized incentive system so as to make up for the lack of promotion, promote the benign movement of the entire organization, to achieve the goal of strategic incentive. And through the model analysis of multiple incentive system is particularly demobilized incentive system in incentive, personnel selection, optimizing the role of the organization system.
\end{abstract}

Keywords-officer; transferred to civilian work; incentive system; reasonable liquidity; promotion incentives

\section{Policy Design Based on Job InCENTIVE System}

The resettlement included incentives for the following considerations:

According to the theory of double factors, the original resettlement system is mainly from the economic compensation of comprehensive existing forces and local conditions set, which belongs to the category of welfare, meet can only achieve "not satisfied", and not on the enthusiasm of staff incentive is the hygiene factors. Therefore, the health care factor into the incentive factor, can mobilize the enthusiasm of the staff work enthusiasm and stimulate the enthusiasm of the work.

The second is according to Fromm's expectation theory, the condition of a man's best motivation is that he thinks that his efforts are likely to lead to a very good performance, good performance is likely to lead to some results; the results have a positive appeal to him. When the promotion probability is very low, individual effort or performance no matter good or bad, it is difficult to get promoted, so the incentive level. But in this case, a good performance may still meet the demobilized excitation conditions to obtain jobs reward, when transferred incentive content appealed to the positive, you will be incentive to change jobs. Therefore, their incentive is a supplement to the promotion incentives, promotion incentives will compensate the beyond one's strength one's power.

The third is demobilized as a major aspect of flow, according to the reality of different periods, the incentive system of be transferred to civilian work at every level in the flow of control. Appropriate incentives can increase jobs for demobilized officers to meet the conditions of the appeal, the increased liquidity. This incentive is based on conditions to limit the length of military service, and thus it can for officers in active service binding, and not the blind pursuit of be transferred to civilian work, home work to disregard.

The incentive system must be multi level jobs, in order to bring continuous power to the officers. Increase the welfare level of demobilized, essentially belongs to pay economic compensation and extension. Therefore, officer's daily wages should less than or equal to its marginal productivity and current demobilized compensation costs. Although wages are rigid, but in the current military wage income is not high, through long-term adjustment, can the soldiers overall benefits gradually tilted to civilian work. In life setting, the first level of demobilized military service award, reaching 15 years. In accordance with the army to promote the model, then its position must be reached the CAMP level officers to achieve.

For each level of the reward, the following method should be set: first, the incentive compatibility constraint should be satisfied. For individuals, the effort can bring benefits, including promotion of expected return, a demobilized reward expected revenue and effort the disutility of should be greater than or equal to try not to return. No effort may lead to two results: job or continue to serve (the highest tenure before). Therefore, under a period of be transferred to civilian work reward expectation income should be greater than jobs gain or continue to promotion of expected return, to the disutility of the difference of income and service. Because of poor promotion after the expected return is along with the improvement of the level of gradually increasing. Therefore, two stages of be transferred to civilian work reward value should also be increased gradually with different levels, namely should tilt.

Secondly, the incentive compatibility constraint should be satisfied with the truth. "Say the truth," the incentive compatibility constraint requirements when a hierarchy of be transferred to civilian work reward conditions are satisfied, the low ability of be transferred to civilian work income should be greater than its continuous service revenue. The demobilized reward gains and the civilian sector income, the original jobs placement treatment, the Ministry of civil affairs of non monetary income should be greater than its continuous service of wage and promotion of expected return and non monetary income. In this case, demobilized reward is mentioned above, the appropriate 
stimulus for increasing, improve the jobs at some point "attractive, to the promotion of the loss of confidence, the officers of the low work efficiency is fully motivation from active service, promote the patency of the flow channel. For high capacity, it still continues to serve more income than income jobs.

Demobilized rewards for specific content, relying on to existing jobs policy of resettlement and compensation policy, as far as possible increase the flexibility and diversity, to improve soldier of be transferred to civilian work benefit levels and funds using a utility to achieve Pareto optimization. In addition can reward the specific content of the set, to guide officers to independent careers in the choice of jobs.

\section{THE MODEL DESIGN}

Firstly, neglecting the difference of staff capacity, demobilized incentive system model has been set up, and demonstration of be transferred to civilian work incentive system incentive mechanism.

When taking the jobs of incentive system, the model is as follows:

Suppose that a person $\alpha$ is a person who is not understood by the military. In this assumption, the total amount of effort to provide the total amount of effort in a certain salary structure, external opportunities and favorable conditions in the period $\mathrm{T}$, at the level of $\mathrm{i}$. $Z\left(e_{i, t}\right)$ stands for the negative effect of the effort , therefore $Z^{\prime}\left(e_{i, t}\right)$ is $>0$ and $Z^{\prime \prime}\left(e_{i, t}\right)>0$. At every point in the career, the individual whose the ability of 1 parameters $\alpha$ must decide whether to continue serving and how much effort. The military must decide whether to let a person continue to service and whether he or she will be promoted.
In the military through the period $\mathrm{T}$ at the level of $\mathrm{I}$, the evaluation of each person and sort of this $\left(E_{i, t}\right)$, and then decide to improve the part of the people $\pi_{t, t}^{*}$ to decide what should be promoted. The probability of an individual's promotion $\left(\pi_{i, t}\right)$ depends on his or her ability and effort and the ability and effort of other people (respectively, $\alpha_{0}$ and $e_{0}$ to express). The military can also pass the assessment $E_{i, t}$ to eliminate those who are not worth a certain minimum $E_{i, t}^{m}$. Finally, military according to the length of military service. Take the deferred payment in the form of demobilized incentive system, at the same time, the minimum amount increased after the reform, increase efforts to eliminate. At this time, closely related to individual jobs income returns and their level of effort. When the probability of promotion is too low, to increase the possibility of obtaining personal rewards through the efforts of demobilized pay higher degree level $E_{i, t}^{m}$. Original of be transferred to civilian work income $L^{\prime}$, for the corresponding level of be transferred to civilian work reward gains, to obtain the possibility $L^{\prime}$, $\operatorname{pr}\left(L^{\prime}\right)$ is positively related to the level of individual efforts, viz $\operatorname{pr}\left(L^{\prime}\right)=\operatorname{pr}\left(e_{i, t}\right)$. If at this time, the length of military service time can not meet the conditions of the award.

The model is a generalization of the incentive model of military officers. Its structure is as follows: the expected value of the future utility of the period $\mathrm{T}$ is:

$$
\begin{gathered}
V_{i, t}^{*}=\Phi_{i, t} E\left(S_{i, t} \mid G_{i, t}^{*}+\varepsilon_{i, t}>0\right)+\left(1-\Phi_{i, t}\right) L_{i, t} \\
\Phi_{i, t}^{*}=\operatorname{pr}\left(E_{i, t}^{m}<E_{i, t}\right) \operatorname{pr}\left(G_{i, t}^{*}+\varepsilon_{i, t}>0\right)=\Phi_{i, t}^{1} \Phi_{i, t}^{2} \\
G_{i, t}^{*}=\pi_{i+1, t+1}\left[\tau^{m}+\delta_{i+1}+W_{i+1, t+1}^{M}+\beta V_{i+1, t+1}^{*}-Z\left(e_{i, t+1}\right)\right] \\
+\left(1-\pi_{i+1, t+1}\right)\left[\tau^{m}+\delta_{i}+W_{i, t+1}^{M}+\beta V_{i, t+1}^{*}-Z\left(e_{i, t+1}\right)\right]-L_{i, t}+\operatorname{pr}\left(L^{\prime}\right) L^{\prime} \\
L_{i, t}=C_{i, t}+R_{i, t}+\Gamma_{t} \\
\operatorname{pr}\left(L^{\prime}\right)=\operatorname{pr}\left(L^{\prime}\right)\left(e_{i, t}\right) \\
\pi_{i+1, t+1}=\pi\left(\alpha, e_{i, t}, \alpha_{i, t}^{0}, e_{i, t}^{0}, \pi_{i+1, t+1}^{*}\right)
\end{gathered}
$$

Use language to describe is that the expected utility $V_{i, t}^{*}$ is a weighted average of the retired to serve the expectation interest return and immediate benefits, the weight $\Phi_{i, t}$ is the military wanted person to continue in service probabilistic ( $\Phi_{i, t}^{1}$ ) and individuals to continue to serve the probability $\left(\Phi_{i, t}^{2}\right.$ ) (the two probabilities are independent of each other) the product. The expected return of the service $G_{i, t}^{*}$ is the weighted average of the high level of salary and the benefits of staying at the current level of interest in the $t+1$ period, and the expected return of the reward for continuing service. These benefits depending on the level of wages and other income $\left(W^{M}\right)$, a certain level of non monetary value $(\delta)$ and the corresponding of be transferred to civilian work reward. The expected return $G_{i, t}^{*}$ is the difference between the expected return and the return of service, and the return of interest is equal to the income of the civil service $\left(C_{i, t}\right)$, the right to obtain the retirement or retirement salary $\left(R_{i, t}\right)$ and the present value of the non monetary value $\left(\Gamma_{t}\right)$ of the civil service. Only when people want to serve again, which is made in the extended service decision of the 
random disturbance. Individuals who have a greater preference for service $\left(\tau^{m}\right)$ are more likely to remain in service. If an individual is in a compulsory retirement point.If an individual is a mandatory retirement level point, $\Phi_{i, t}=0$ and. $V_{i, t}^{*}=L_{i, t}$.

In the period $\mathrm{t}$ at the individual expectations of future utility as follows:

$$
\tau^{m}+W_{i, t}^{M}+\beta V_{i, t}^{*}-Z\left(e_{i, t}\right)+\operatorname{pr}\left(L^{\prime}\right) L^{\prime}
$$

Individuals in the period $\mathrm{T}$ to provide an effort to maximize the expected future utility of individuals. Analysis of equation (2) and effort level is related to the content can draw the incentive factors, first of all the efforts of the increase in the probability of promotion while promotion means higher monetary and non monetary compensation. Secondly, efforts to reduce the failed to meet minimum performance standards rather than voluntary retirement probability, non voluntary retirement probability increases with the decrease of the possibility of demobilized reward.
For the low level of the young officer, there is a problem of low incentive degree due to the high probability of promotion. Demobilized reward belongs to delay give salary, increases the expected return to serve, enhancement to prolong the service life of power, reduces the mobility of the young officer; and the first reward gear set to 15 years, meet the probability is close to 0.5 , the efforts of the marginal utility of a good. So it is a better incentive effect.

For high grade officers, if not of be transferred to civilian work incentive system, combined with officer revenue incentive model, type $\tau^{m}+W_{i, t}^{M}+\beta V_{i, t}^{*}-Z\left(e_{i, t}\right)$ said in period $\mathrm{T}$, individual's expected future utility, personal in period $\mathrm{t}$ provide in an effort to make the formula to maximize, to improve the level of effort can increase the probability of promotion in order to improve the expected future utility. However, if the individual is promoted to a level of low probability $\pi_{(i+1, t+1)}$, assuming that as 0 , that is:

$$
\begin{aligned}
G_{i, t}^{*} & =\pi_{i+1, t+1}\left[\tau^{m}+\delta_{i+1}+W_{i+1, t+1}^{M}+\beta V_{i+1, t+1}^{*}-Z\left(e_{i, t+1}\right)\right]+\left(1-\pi_{i+1, t+1}\right)\left[\tau^{m}+\delta_{i}+W_{i, t+1}^{M}+\beta V_{i, t+1}^{*}-Z\left(e_{i, t+1}\right)\right]-L_{i, t} \\
& =\tau^{m}+\delta_{i}+W_{i, t+1}^{M}+\beta V_{i, t+1}^{*}-Z\left(e_{i, t+1}\right)-L
\end{aligned}
$$

That is to continue to serve the expected return is the current return and return of the benefits of the poor, the type of the content, and efforts to increase the function of the promotion probability disappeared, and its increase can

only lead to $Z\left(e_{i, t+1}\right)$ increased, can not bring any gains, so the officer lost the motivation to work. But if you take the job incentive system, even if the promotion probability is close to 0 , there are:

$$
\begin{aligned}
& G_{i, t}^{*}=\pi_{i+1, t+1}\left[\tau^{m}+\delta_{i+1}+W_{i+1, t+1}^{M}+\beta V_{i+1, t+1}^{*}-Z\left(e_{i, t+1}\right)\right] \\
& +\left(1-\pi_{i+1, t+1}\right)\left[\tau^{m}+\delta_{i}+W_{i, t+1}^{M}+\beta V_{i, t+1}^{*}-Z\left(e_{i, t+1}\right)\right]-L_{i, t}+\operatorname{pr}\left(L^{\prime}\right) L^{\prime} \\
& \quad=\tau^{m}+\delta_{i}+W_{i, t+1}^{M}+\beta V_{i, t+1}^{*}-Z\left(e_{i, t+1}\right)-L_{i, t}+\operatorname{pr}\left(L^{\prime}\right) L^{\prime}
\end{aligned}
$$$$
\operatorname{pr}\left(L^{\prime}\right)=\operatorname{pr}\left(L^{\prime}\right)\left(e_{i, t}\right)
$$

there is a positive correlation with the degree of effort. Therefore, when the probability of promotion is small lead officer lost promotion incentives, the let through efforts to get the demobilized additional incentives for the probability, the probability than the probability of promotion to high (specific size can be controlled), it still have the incentive to change jobs. That when officers feel that their own can not be promoted, it will continue to maintain a certain level of effort, make their demobilized military service can meet the closest to the next stage of be transferred to civilian work incentive to give additional incentives for the life.

And when $\operatorname{pr}\left(L^{\prime}\right)=1$, that is, to achieve a demobilized reward conditions, lower level jobs reward probability will start from zero, according to degree of efforts to gradually accumulate. At this point, there are two individual choice, that is, choose to quit active service or continue to serve. At this time, the participants appeared in the "high capacity" and "low power" distinction. "High power" and "low power" are relative concepts, and are the high ability and low ability of competing states in the same level.

High ability and low ability of case analysis is used to demonstrate demobilized incentive system in the staff separation type role, which embodies the function of this system in the liquidity structure optimization. When the internal revenue is higher than the external income, individuals have the motivation to extend the service. But due to promotion probability limit and the highest tenure restrictions and forces for liquidity considerations, the people will be part of the forced to change jobs. The basis is through the assessment of compulsory jobs to weed out those who are not up to the value of a minimum amount of people. The low ability to continue serving in the service will be a false signal to the organization, if it continues to serve a greater profit. Demobilized incentive system in hopes of promoting officers self sorting, and the formation of high ability and low ability of separation behavior to increase active jobs, make the organization flow, organization, personnel structure optimization.

Assuming that all the participants are rational, the purpose is to pursue the maximization of present value. At the same time, they have a relatively clear understanding of their own as well as their competitors' ability and strength, and can be more reasonable to self ranking, and the individual's ability to belong to private information.

Because of the lack of liquidity is mainly reflected in the promotion of a low probability of senior officers, so for this situation analysis. Low ability to recognize to the marginal utility of the probability of promotion is very low, simply said that normal promotion hopes, not to will be 
forced to change jobs, if there is no incentive to change jobs, differences between two kinds of behavior choice mainly reflected demobilized after the income and the period of service received benefit difference (formula 4-3). This difference may is positive may be negative. And after demobilized excitation set, differences between two kinds of behavior choice in addition to demobilized after the income and service period earnings differences and work to get the expected return of the demobilized incentive content, difference widening. Just by trying to get jobs reward probability is not very low, low ability who choose to continue to serve the motivational enhancement, and work actively to maintain.

When meeting the demobilized reward conditions, officer behavior (to continue in service jobs), forces have (promotion, retention, mandatory retirement). When the officer enters the next stage of reward, because the reward content itself has a tilt, for the military, if you keep the original stage of the reward ratio, the cost will increase, while the total revenue decreased. Therefore, the military will improve the output for the lowest limit standard, to reduce the proportion of bonus stage jobs. The minimum output limit $E_{i, t}^{m 2}$ for the new period, the minimum output required for the promotion, is $E_{i, t}^{m 3}$, then, $E_{i, t}^{m 3}>E_{i, t}^{m 2}>E_{i, t}^{m}$. Because of the promotion probability $E_{i, t}^{m 2}$ is small, the degree $E_{i, t}^{m 3}$ is higher. $\alpha$ Designed for personal ability, $\alpha^{h}$ as high capacity of the type, $\alpha^{l}$ as low capacity of the type, $e^{\prime}$ for the ability to work hard, $e^{\prime \prime}$ for the low level of effort, $Z^{\prime}\left(e_{i, t}\right)$ as the representative of the negative utility $Z^{\prime \prime}\left(e_{i, t}\right)$, $E_{i, t}^{m 2}=E_{i, t}^{m 2}(\alpha, e)$. In order to be a high power, or to stay in the army, to provide $E_{i, t}^{m 2}$ at least a greater than output. As shown in Fig .5.1, when troops to provide personal income $W^{*}$, low ability person pretending to be of high ability, will have to pay the effort level $e^{\prime \prime}$,
$Z^{\prime \prime}\left(e_{i, t}\right), Z^{\prime}\left(e_{i, t}\right)$, decreased the total utility of low capacity, if capacity is low in order to meet the minimum disutility $E_{i, t}^{m 2}$ resulting in $W^{*}$ less than jobs income, and losing the participation constraint and retire from active service. And for high capacity, will continue to serve. Through several stages of automatic selection process, control forced demobilized proportion and transferred to reward scale to control minimum value increased gradually, continue to survival of the fittest, organizational structure optimization.

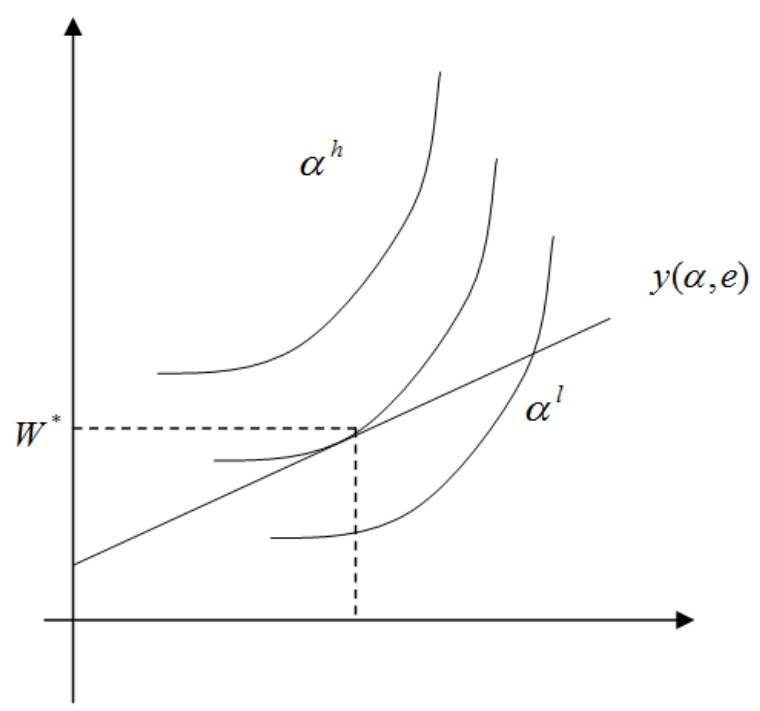

Figure 1. Separation Equilibrium Under Asymmetric Information

When the low ability to meet the previous stage of be transferred to civilian work reward conditions can foresee their ability and willing to pay the effort level makes $\operatorname{pr}\left(L^{\prime}\right)$ and $\pi_{i+1, t+1}$ are very small, close to zero, through its efforts to continue in service can not be used to increase access to jobs rewards can obtain expected return, also can not gain promotion probability of expected return, there are:

$$
\begin{aligned}
& G_{i, t}^{*}=\pi_{i+1, t+1}\left[\tau^{m}+\delta_{i+1}+W_{i+1, t+1}^{M}+\beta V_{i+1, t+1}^{*}-Z\left(e_{i, t+1}\right)\right]+\left(1-\pi_{i+1, t+1}\right) \\
& {\left[\tau^{m}+\delta_{i}+W_{i, t+1}^{M}+\beta V_{i, t+1}^{*}-Z\left(e_{i, t+1}\right)\right]-L_{i, t}+\operatorname{pr}\left(L^{\prime}\right) L^{\prime}} \\
& { }^{m}+\delta_{i}+W_{i, t+1}^{M}+\beta V_{i, t+1}^{*}-Z\left(e_{i, t+1}\right)-L_{i, t}
\end{aligned}
$$

When $G_{i, t}+\varepsilon_{i, t}<0$ the individual will choose to retire. $\tau^{m}+\delta_{i+1}+W_{i+1, t+1}^{M}+\beta V_{i+1, t+1}^{*}-Z\left(e_{i, t+1}\right)$ $\tau^{m}+\delta_{i}+W_{i, t+1}^{M}+\beta V_{i, t+1}^{*}-Z\left(e_{i, t+1}\right) \quad, \quad G_{i, t}^{*} \quad$ Decrease. Therefore, the choice of the possibility of more jobs.

For the high ability to promotion probability in the marginal efficiency of relatively high, after reaching a stage of be transferred to civilian work reward conditions, and their expectations of income still include efforts to promotion probability expected revenue. Therefore, people with high capacity will choose to continue to service and provide high levels of best effort.

In simple terms, namely in officers are expected to reach the demobilized excitation conditions, promotion incentive factors, although very small, but is likely to reward jobs, which produces the incentive. When meeting the demobilized reward conditions, low capacity expected to can not get a promotion and reward jobs, or is not willing to pay the corresponding level of effort, will choose to get the current reward demobilized after active 
jobs. For people with high capacity, even with the promotion probability is very small, but demobilized reward probability still exist, which still has incentive to work hard. Thus, the behavior of the high ability and low ability is separated, and the low productivity of the marginal productivity can keep the medium level of effort, and will be willing to leave the army at a certain point, thus increasing the flow space of the next level officer. High capacity will always provide high level of effort, until become competitors in the low". And the low ability of the organization, more efficient, will make the level of the officers of the following levels of promotion channels more smooth.

Therefore, their incentive system not only can be used as a supplementary promotion incentives, but also can promote the rational flow of. And according to the reality of the situation, such as the flow adjustment to adjust the demand of demobilized incentives.

\section{REFERENCES}

[1] Lou Mang ZhanXiaoJun. Read the "Security" Demobilized Officers at the Grass-roots Level [J]. China talent, 2013:26-27.

[2] Zou Shiwei. Resettlement of demobilized officers problems and Countermeasures [D]. Hunan Normal University, 2014
[3] Tan Yimin. The research on the incentive mechanism of the grassroots officers of the armed police forces at the Hunan University, [D]., 2013

[4] Liu Xiong. Officers transferred to civilian work in new period research [D]. The system of hunan university, 2013.

[5] Luo Jin. Independent demobilized army officers management service work of profession research [D]. Yunnan university, 2014.

[6] Gao Shui Demobilized Army Officers in China Human Resources Development and Management Analysis [J]. Journal of Oriental culture, 2015) : 93.

[7] Liu Xiong Liu Zongsheng, Li Shiyuan. Demobilized army officers in the new period as the plight of the placement and routing $[\mathrm{J}]$. Journal of military political science research, 2013 01:42-61.

[8] Wang Xinghua, Zhang Zhe. Think about the military human capital to participate in the distribution of income of military assets and financial, 2012,02:102.

[9] Wang Xin Human Resources Management "strategic incentive" [ J] enterprise economy, 2012,05: 83-85.

[10] Liu Xuefeng, Gu Jianyi, Liu Shufang. Soldiers serving incentive mechanism design and policy advice $[\mathrm{J}]$. Journal of military and economic studies, 2012, 05:21-24.

[11] Ma Yingxing. Theory of military human capital investment risk and guard against $[\mathrm{J}]$. Journal of military and economic studies, 2012, 10, 15 and 17.

[12] Ma Sibei. Armed police officer incentive mechanism research [D]. Jilin university of finance and economics, 2013. 